\title{
Is There a Relationship Between Ovarian Reserve and Blood Groups in Infertile Patients?
}

\author{
Ozgur KAN¹, Umit GORKEM¹, Aysegul ALKILIC ${ }^{2}$, Deniz TASKIRAN, Ozgur KOCAK¹, Engin YILDIRIM1, \\ Cihan TOGRUL ${ }^{1}$
}

Corum, Turkey

\section{ABSTRACT}

OBJECTIVE: Evaluation of ovarian reserve in infertile patients had become an important concept in assisted reproductive techniques success work-up. Recent studies reported an association between blood type and ovarian reserve. Therefore, the aim of this study was to analyze the relationship between blood type and ovarian reserve in infertile patients.

STUDY DESIGN: In this retrospective, observational and single-cenre study, a total of 311 women who were applied for fertility seek between January 2018 and November 2018 were included. As a threshold of ovarian reserve, serum follicle stimulating hormone levels $(>10 \mathrm{mlU} / \mathrm{mL})$ and antral follicle counts $(\leq 5)$ at early follicular phase were taken to reflect diminished ovarian reserve. The main outcome was the association between blood types and ovarian reserve. Secondary outcomes were biochemical and clinical pregnancy rates.

RESULTS: There was no relationship between blood types and follicle stimulating hormone levels. Elevated follicle stimulating hormone levels were associated with only age and antral follicle count. Similar to the results of ovarian reserve, biochemical and clinical pregnancy outcomes are not affected by blood groups and Rhesus factor.

CONCLUSION: Patients' blood type did not have any impact on ovarian reserve. In addition, neither blood type nor rhesus factor have an effect on predicting pregnancy outcomes in assisted reproductive techniques, patients.

Keywords: ABO-blood group system, Assisted reproductive techniques, Infertility, Ovarian reserve

Gynecol Obstet Reprod Med 2019;25(3):148-152

\section{Introduction}

Ovarian reserve reflects the quantity and quality of oocytes available for achieving a pregnancy (1). While several tests and biochemical markers have used to determine ovarian reserve, female age still remains the most important predictor for assisted reproductive techniques (ART) success (2). In fact, the

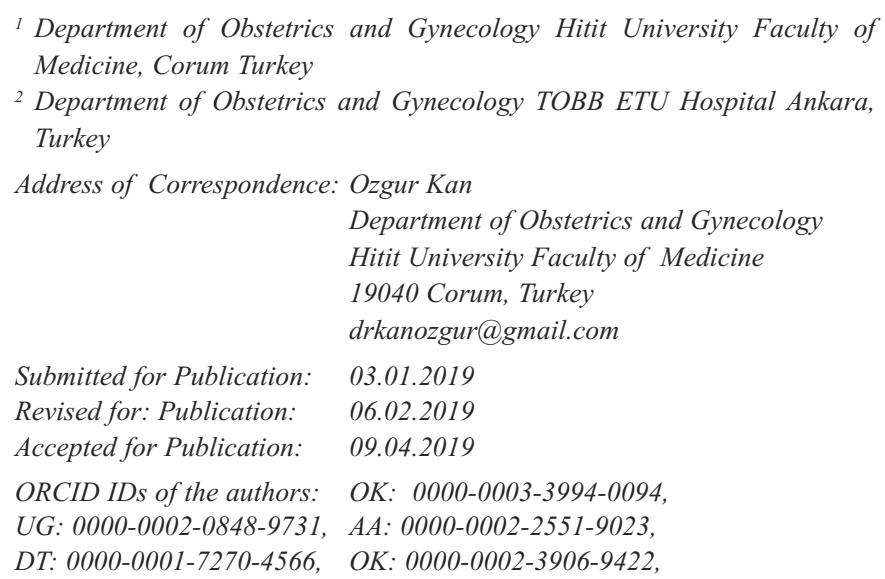

\begin{tabular}{|c|c|}
\hline Quick Response Code: & Access this article online \\
\cline { 2 - 2 } & Website: www.gorm.com.tr \\
e- mail: info@gorm.com.tr
\end{tabular}

number of follicles in ovaries reduces dramatically with advanced ages. Predominantly, a variety of measures, such as follicle stimulating hormone (FSH), anti-Mullerian hormone (AMH), Inhibin-B levels, and antral follicle count (AFC) with ultrasound are used to assess ovarian reserve $(3,4)$. Ovarian reserve tests also help clinicians about predicting ovarian response for the treatment protocols and ART outcomes (5).

Diminished ovarian reserve (DOR) usually characterized by FSH level $>10 \mathrm{IU} / \mathrm{L}$ at the early follicular phase (6). While measurement of FSH level is applicable, highly reproducible and most exploited parameter for evaluating ovarian reserve status in infertility practice, the most important drawback of this approach is that this hormone has a significant cycle-tocycle variation (7). Due to this reality, combining FSH measurement with evaluation of the AFCs is thought to be more feasible in evaluating ovarian reserve.

Diminished ovarian reserve is associated with factors such as endometriosis, autoimmune diseases, infections and toxins, smoking, history of chemotherapy and radiotherapy due to malignancies and prior ovarian surgery (8-10). Eventually,

How to cite this article: Kan O. Gorkem U. Alkilic A. Taskiran D. Kocak O. Yildirim E. Togrul C. Is There a Relationship Between Ovarian Reserve and Blood Groups in Infertile Patients? Gynecol Obstet Reprod Med. 2019;25(3): 148-152 
this diagnosis transforms into premature ovarian failure, which has several impacts on women health, including early onset menopause, osteoporosis and cardiovascular disease (11). In case of DOR, clinicians should inform the couples about their relatively low possibility to obtain a pregnancy and update them about their options for treatment modalities.

As a known fact, ABO blood group antigens are glycoproteins which are expressed in many different tissues and cells such as epithelial cells, vascular endothelium and neurons in addition to erythrocyte membrane surfaces (12). Based on this fact, the relationship to different pathologies to blood groups has been of interest to researchers, and its implications on ovarian functions were evaluated in different gynecologic conditions. In an earlier study, it was reported that blood group A was more common in patients with ovarian hyperstimulation syndrome (OHSS) (13). Later, endometriosis has been reported to be more frequent in patients with blood group A (14).

In 2011, Nejat et al. come up with a finding that there was a relationship between ovarian reserve and blood types. They stated that antigen A was protective against the development of DOR, while O blood group was a risk factor for DOR occurrence (15). Subsequent to that report, Timberlake et al. did not find an association between the blood type $\mathrm{O}$ and increased occurrence of DOR (16). After these first data, other researchers investigated this issue and reported divergent results. Therefore, we aimed to evaluate whether ovarian reserve and ART outcomes are associated with certain ABO blood groups.

\section{Materials and Method}

Female patients undergoing ovulation induction for infertility treatment at a university hospital from January 2018 to September 2018 were included in this retrospective study. The study was approved by the institutional research ethics committee, which was in accordance with the Declaration of Helsinki, 2013 (Brazil version) (2018-143).

Three hundred and eleven infertile patients between 20 and 42 years of age were included in this study, including anovulatory women and eumenorrheic women with a diagnosis of unexplained infertility for whom ovulation induction with gonadotrophins were indicated. Patients with prior chemotherapy, radiotherapy and ovarian surgery for any indication, history of severe autoimmune or chronic disease, incomplete data or records and lastly lost to follow-up were excluded. Written informed consents were obtained from all participant patient.

Data for each patient, including age, body mass index (BMI), duration of subfertility, AFCs, blood type, and Rhesus $(\mathrm{Rh})$ factor were collected from the patient charts and electronic medical records. The primary outcome for analyses was association between ovarian reserve and blood types. DOR was defined by a day-3 FSH level of $>10 \mathrm{mIU} / \mathrm{mL}$ and number of AFCs $\leq 5$ was taken to reflect DOR $(6,7)$. Serum FSH $(\mathrm{mIU} / \mathrm{mL})$ and estradiol $(\mathrm{mIU} / \mathrm{mL})$ levels were measured on the third day of the menstrual cycle. Pelvic ultrasound examination was carried out by using a Toshiba Xario 100 (Toshiba Medical Systems Corporation, Nasu, Japan) with a 7.5-MHz vaginal transducer and by the same specialists at the early follicular phase of the menstrual cycle. On the $3^{\text {rd }}$ day of the cycle, AFC was the sum of antral follicles measuring 2-10 $\mathrm{mm}$ in diameter. Secondary outcomes included biochemical pregnancy rate (BPR) which was defined as a positive serum beta hCG, but without development of a gestational sac identifiable by sonography, secondly, clinical pregnancy rate (CPR) which was defined with a confirmed gestational sac, visible fetal pole with cardiac activity, and lastly, live birth rate (LBR).

\section{Statistical Analysis}

Statistical analysis was performed using Statistical Package for the Social Sciences (SPSS) software, version 22.0 for Windows (SPSS, Inc., Chicago, IL, USA). The Kolmogorov-Smirnov and Shapiro-Wilk tests were used to test the normality of distribution. In the statistical comparison of categorical variables according to the ovarian reserve status, the chi-square test was performed. The Mann Whitney U test was used for statistical comparison of quantitative measurements to determine the association according to FSH groups. When the FSH variable was considered as dependent variable and other variables were considered as independent variables, prediction model was tested by logistic regression analysis. The statistical significance of differences in the distribution of variables including BPR, CPR, and LBR between blood group types was evaluated using the Pearson chisquared test. A $p$-value of $<0.05$ was accepted as statistically significant.

\section{Results}

Baseline demographical and clinical characteristics of the patients are shown in table I. Overall mean age and BMI of the study cohort were $29.3 \pm 5.6$ years and $24.3 \pm 4.6 \mathrm{~kg} / \mathrm{m}^{2}$, respectively. The overall distribution of blood groups in the cohort were as follows: $45.9 \%$ (Group A), 20.2\% (Group B), 6.4\% (Group AB), 27.3\% (Group O). Of the 311 patients, 274 (88.1\%) were Rhesus factor positive, while 37 (11.8\%) patients were Rhesus factor negative.

As expected, patients with DOR had significantly higher levels of FSH $(12.9 \pm 3.7$ vs $6.1 \pm 1.7, p<0.001)$ and lower AFC than patients with normal ovarian reserve $(8.1 \pm 5.5$ vs $15.7 \pm 7.2, p<0.001$ ) (Table I). There were no significant differences among duration of infertility and other hormone levels including luteinizing hormone $(\mathrm{LH})$ and estradiol $(p=0.433$, $p=0.353$ and $p=0.146$, respectively).

As shown in table II, participants were additionally divided into subgroups based on their antigenic status. Similarly, to the blood type results, neither A (blood type $A+A B$ ) antigen 
nor $\mathrm{B}$ antigenic status (blood type $\mathrm{B}+\mathrm{AB}$ ) were associated with ovarian reserve ( $p=0.53, p=0.80$, respectively).

Factors associated with elevated FSH levels are analyzed by logistic regression tests as presented in table III. Elevated FSH levels were significantly associated with advanced age and lower AFC ( $p<0.001$, for both), while not associated with LH and estradiol levels, blood group types and Rhesus factor ( $p=0.091, p=0.137, p=0.909$ and $p=0.219$, respectively).
Table IV shows the association between blood group types and pregnancy outcomes. No difference was observed among four blood type groups in terms of biochemical (BPR), clinical pregnancy (CPR) and live birth rates (LBR) (for BPR; $p=0.876$, for CPR; $p=0.895$ and for LBR; $p=0.433$, respectively). In addition, there was no significant correlation between Rhesus factor and pregnancy outcomes $(p=0.238$, for BPR).

Table I: Baseline characteristics of the patients with different ovarian reserve types

\begin{tabular}{|c|c|c|c|}
\hline & $\begin{array}{l}\text { Normal ovarian reserve group } \\
\qquad(\mathrm{n}=278)\end{array}$ & $\begin{array}{l}\text { Diminished ovarian reserve group } \\
\qquad(\mathrm{n}=33)\end{array}$ & $\begin{array}{c}p \\
\text { value }\end{array}$ \\
\hline Age (years) & $28.9 \pm 5.3$ & $32.1 \pm 6.7$ & $0.031^{*}$ \\
\hline $\mathrm{BMI}\left(\mathrm{kg} / \mathrm{m}^{2}\right)$ & $24.1 \pm 4.4$ & $25.9 \pm 5.6$ & 0.114 \\
\hline $\mathrm{FSH}(\mathrm{mlU} / \mathrm{mL})$ & $6.1 \pm 1.7$ & $12.9 \pm 3.7$ & $<0.001^{*}$ \\
\hline $\mathrm{LH}(\mathrm{mlU} / \mathrm{mL})$ & $5.8 \pm 4.3$ & $6.4 \pm 3.2$ & 0.335 \\
\hline E2 $(\mathrm{pg} / \mathrm{mL})$ & $49.8 \pm 62.8$ & $41.8 \pm 23.1$ & 0.092 \\
\hline AFC & $15.7 \pm 7.2$ & $8.1 \pm 5.5$ & $<0.001^{*}$ \\
\hline \multicolumn{4}{|c|}{ Blood group types } \\
\hline $\mathrm{O}$ & $76(27.3 \%)$ & $9(27.2 \%)$ & \\
\hline$A$ & $128(46.0 \%)$ & $15(45.4 \%)$ & \\
\hline B & $55(19.7 \%)$ & $8(24.2 \%)$ & \\
\hline$A B$ & $19(6.8 \%)$ & $1(3.0 \%)$ & 0.812 \\
\hline \multicolumn{4}{|l|}{ Rh factor } \\
\hline Positive & $247(88.8 \%)$ & 27 (81.8\%) & \\
\hline Negative & $31(11.1 \%)$ & $6(18.1 \%)$ & 0.238 \\
\hline
\end{tabular}

Values are shown as mean \pm standard deviation. BMI: Body mass index, FSH: Follicle stimulating hormone, LH: Luteinizing hormone, E2: estradiol, AFC: Antral follicle count, Rh: Rhesus. * $p$-values (Student's $t$-test and Pearson's $X^{2}$ test) indicate statistically significant $(p<0.05)$.

Table II: Blood type antigen distribution and patient characteristics according to ovarian reserve status

\begin{tabular}{lccc}
\hline & $\begin{array}{c}\text { Normal ovarian reserve group } \\
(\mathrm{n}=278)\end{array}$ & $\begin{array}{c}\text { Diminished ovarian reserve group } \\
(\mathrm{n}=33)\end{array}$ & $\begin{array}{c}p \\
\text { value }\end{array}$ \\
\hline $\begin{array}{l}\text { Age (years) } \\
\begin{array}{l}\text { Blood Group } \\
0\end{array}\end{array}$ & $28( \pm 5.4)$ & $32( \pm 6.8)$ & $\mathbf{0 . 0 0 9 *}$ \\
$\begin{array}{l}\text { A antigen } \\
\text { (blood types } A+A B)\end{array}$ & $76(27 \%)$ & $9(27 \%)$ & 0.98 \\
$\begin{array}{l}\text { B antigen } \\
\text { (blood types } B+A B)\end{array}$ & $147(52 \%)$ & $16(48 \%)$ & 0.53 \\
\hline
\end{tabular}

Age is presented as mean $\pm S D$; other variables are shown as number $(n)$ and percentage (\%).

* $p$-values (Pearson's $X^{2}$ test) indicate statistically significant $(p<0.05)$.

Table III: Logistic regression analyses between FSH and predictor variables of the study

\begin{tabular}{|c|c|c|c|c|c|c|}
\hline & \multirow[b]{2}{*}{$\beta$} & \multirow[b]{2}{*}{ SE } & \multirow[b]{2}{*}{$p$-value } & \multirow[b]{2}{*}{$\exp (\beta)$} & \multicolumn{2}{|c|}{$95 \% \mathrm{Cl}$ for $\exp (\beta)$} \\
\hline & & & & & Lower & Upper \\
\hline Age & -0.018 & 0.049 & $0.009^{*}$ & 0.982 & 0.892 & 1.082 \\
\hline $\mathrm{LH}$ & 0.339 & 0.135 & 0.091 & 1.403 & 1.077 & 1.828 \\
\hline E2 & -0.013 & 0.014 & 0.137 & 0.987 & 0.961 & 1.014 \\
\hline AFC & 0.119 & 0.174 & $<0.001^{*}$ & 1.127 & 0.801 & 1.585 \\
\hline Blood type & -0.043 & 0.373 & 0.909 & 0.958 & 0.461 & 1.992 \\
\hline Rh factor & 0.934 & 0.759 & 0.219 & 2.543 & 0.575 & 11.256 \\
\hline
\end{tabular}

FSH: Follicle stimulating hormone, LH: Luteinizing hormone, E2: estradiol, AFC: Antral follicle count, Rh: Rhesus, SE: Standard error, Cl: Confidence interval, * $p$-values indicate statistically significant $(p<0.05)$. 
Table IV: Pregnancy outcomes for blood group types

\begin{tabular}{|c|c|c|c|c|c|c|c|}
\hline & & & \multicolumn{4}{|c|}{ Blood group type } & \multirow{2}{*}{$\begin{array}{c}p \\
\text { value }\end{array}$} \\
\hline & & & 0 & $A$ & B & $A B$ & \\
\hline \multirow{4}{*}{ Biochemical pregnancy } & \multirow{2}{*}{$(-)$} & $\mathrm{n}$ & 56 & 96 & 41 & 15 & \multirow{4}{*}{0.876} \\
\hline & & $\%$ & 26.9 & 46.2 & 19.7 & 7.2 & \\
\hline & \multirow{2}{*}{$(+)$} & $\mathrm{n}$ & 28 & 47 & 22 & 5 & \\
\hline & & $\%$ & 27.5 & 46.1 & 21.6 & 4.9 & \\
\hline \multirow{4}{*}{ Clinical pregnancy } & \multirow{2}{*}{$(-)$} & $\mathrm{n}$ & 57 & 101 & 44 & 15 & \multirow{4}{*}{0.895} \\
\hline & & $\%$ & 26.3 & 46.5 & 20.3 & 6.9 & \\
\hline & \multirow{2}{*}{$(+)$} & $\mathrm{n}$ & 28 & 42 & 19 & 5 & \\
\hline & & $\%$ & 29.8 & 44.7 & 20.2 & 5.3 & \\
\hline \multirow{4}{*}{ Live birth rates } & \multirow{2}{*}{$(-)$} & $\mathrm{n}$ & 70 & 124 & 55 & 19 & \multirow{4}{*}{0.433} \\
\hline & & $\%$ & 26.1 & 46.3 & 20.5 & 7.1 & \\
\hline & \multirow{2}{*}{$(-)$} & $\mathrm{n}$ & 15 & 19 & 7 & 1 & \\
\hline & & $\%$ & 35.7 & 45.2 & 16.7 & 2.4 & \\
\hline
\end{tabular}

\section{Discussion}

Our study has demonstrated that there is no association between ABO blood types and ovarian reserve markers. Neither blood types nor A or B antigen contributes as a risk or protective factor for DOR. In addition, blood groups and Rhesus factor do not affect pregnancy outcomes.

In 2011, Nejat et al. reported that blood types with the A antigen are protective for ovarian reserve, while blood type $\mathrm{O}$ appears to be associated with elevated FSH levels and DOR (15). They cited an earlier study which suggested that blood group A was significantly more frequent among patients with OHSS (13). In this report, Binder and colleagues had explained the association between the blood types and OHSS with genetic inherence, enzymes and proteins, such as group A transferase, glycosyl transferase and $\mathrm{N}$-acetyl glucosaminyl transferase-1 (17). However, Bellver et al. reported that they did not find any association between blood group antigens and OHSS in a cohort with similar clinical and demographical characteristics (18). The results of the data on the relationship between the development of blood groups and OHSS occurrence are contradictory in the existing literature. Another study with a large cohort included approximately 35.000 participants, while blood type $\mathrm{O}$ was being found to be significantly protective for DOR occurrence, potential risk of DOR was significantly higher in patients with $\mathrm{B}$ antigen (blood type $\mathrm{B}$ or AB) (19). The authors also added that A antigen was not associated with ovarian reserve status.

In our study, demographical data were similar between blood types. Mean age, BMI, duration of subfertility between blood type subgroups were analogous. Blood type subgroup ratios between FSH $\leq 10 \mathrm{mIU} / \mathrm{mL}$ and $\mathrm{FSH}>10 \mathrm{mIU} / \mathrm{mL}$ groups were vicinal. From that result, we did not observe any relationship in groups, which has similar demographical data. In addition, we did not observe any association between ovarian reserve and antigenic status independent of blood groups. In parallel with our findings, Timberlake et al. and some other researchers reported similar results (16). They defined DOR as FSH $>10 \mathrm{mIU} / \mathrm{mL}$ in their study population and they reported female age and lower AFC were associated with DOR. Sengül et al. reported similar results and their findings showed only female age had an impact on ovarian reserve (20).

We have also investigated the relationship between blood types and pregnancy outcomes and we did not find an association in terms of clinical pregnancy rates, and live birth rates. Similar to our findings, Spitzer and colleagues also failed to show any association between blood group antigens and IVF outcomes, including collected oocyte counts and LBR (21). In the light of their results, they emphasized that it would not be accurate to estimate the fertility potential and presumption of pregnancy may be reduced on certain blood groups.

This study has some limitations to be mentioned. Firstly, our findings are limited by its relatively small sample size and further prospective studies with extended populations are warranted. Secondly and most importantly, we did not analyze $\mathrm{AMH}$ levels of the participants due to lack of financial resources. Since only one-third of our study population had AMH values, we could not add this evaluation to the study. To get over that lacking data, we added AFC to FSH levels to measure ovarian reserve in the first place.

In conclusion, we observed that there is no association between blood types and ovarian reserve markers. As previously revealed, age and AFCs have predictive value in evaluating ovarian reserve status. Furthermore, blood groups have limited efficacy in predicting pregnancy outcomes in infertile pa- 
tients. However, further prospective studies and meta-analyses are needed in order to clarify whether there is any relationship between blood groups and ovarian reserve markers.

Conflict of interest: The authors report no conflict of interest. Author Contributions: OK: Concept, design, writer. UG: Supervision, design, writer. AA: Concept, statistical analysis and data interpretation. DT: Data collection and processing, literature review. OK: Data collection and processing, literature review. EY: Statistical analysis and data Interpretation, language editing, CT: Literature review, data collection.

\section{References}

1. Macklon NS, Fauser BC. Ovarian reserve. Semin Reprod Med. 2005; 23(3):248-56.

2. Levi AJ, Raynault MF, Bergh PA, Drews MR, Miller BT, Scott RT Jr. Reproductive outcome in patients with diminished ovarian reserve. Fertil Steril. 2001;76(4):666-9.

3. Johnson NP, Bagrie EM, Coomarasamy A, Bhattacharya S, Shelling AN, Jessop S, et al. Ovarian reserve tests for predicting fertility outcomes for assisted reproductive technology: The International Systematic Collaboration of Ovarian Reserve Evaluation protocol for a systematic review of ovarian reserve test accuracy. BJOG. 2006;113 (12):1472-80.

4. Practice Committee of the American Society for Reproductive Medicine. Testing and interpreting measures of ovarian reserve: a committee opinion. Fertil Steril. 2012;98(6):1407-15.

5. Committee on Gynecologic Practice. Committee Opinion No. 618: Ovarian reserve testing. Obstet Gynecol. 2015;125(1):268-73.

6. Greenseid K, Jindal S, Zapantis A, Nihsen M, Hurwitz J, Pal L. Declining ovarian reserve adversely influences granulosa cell viability. Fertil Steril. 2009;91(6):2611-5.

7. Bancsi LF, Broekmans FJ, Mol BW, Habbema JD, te Velde ER. Performance of basal follicle-stimulating hormone in prediction of poor ovarian response and failure to become pregnant after in vitro fertilization: a meta-analysis. Fertil Steril. 2003;79(5):1091-100.

8. Chiarelli AM, Marrett LD, Darlington G. Early menopause and infertility in females after treatment for childhood cancer diagnosed in 1964-1988 in Ontario, Canada. Am J Epidemiol. 1999;150(3):245-54.

9. Lin K, Samantha B, Sammel MD, Barnhart KT. Risk factors for diminished ovarian reserve and the role of en- dometriosis. Fertil Steril. 2010;94(Suppl): S63.

10. Ergenoglu AM, Yeniel O, Turan V, Demirtaş G, Akman L, Terek MC, et al. Assessment of the effects of chemotherapy on ovarian reserve in rats. Gynecol Obstet Reprod Med. 2014;20(1):29-33.

11. Shuster LT, Rhodes DJ, Gostout BS, Grossardt BR, Rocca WA. Premature menopause or early menopause: longterm health consequences. Maturitas. 2010;65(2):161-6.

12. Franchini M, Liumbruno GM. ABO blood group: old dogma, new perspectives. Clin Chem Lab Med. 2013; 51(8):1545-53.

13. Binder H, Flegel WA, Emran J, Müller A, Dittrich R, Beckmann MW, et al. Association of blood group A with early onset ovarian hyperstimulation syndrome. Transfus Clin Biol. 2008;15(6):395-401.

14. Matalliotakis I, Cakmak H, Goumenou A, Sifakis S, Ziogos E, Arici A. ABO and Rh blood groups distribution in patients with endometriosis. Arch Gynecol Obstet. 2009;280(6):917-9.

15. Nejat EJ, Jindal S, Berger D, Buyuk E, Lalioti M, Pal L. Implications of blood type for ovarian reserve. Hum Reprod. 2011;26(9):2513-7.

16. Timberlake KS, Foley KL, Hurst BS, Matthews ML, Usadi RS, Marshburn PB. Association of blood type and patient characteristics with ovarian reserve. Fertil Steril. 2013;100(6):1735-9.

17. Williams SA, Stanley P. Oocyte-specific deletion of complex and hybrid N-glycans leads to defects in preovulatory follicle and cumulus mass development. Reproduction. 2009; 137(2):321-31.

18. Bellver J, Ferrando M, Garrido N, Pellicer A. Blood group and ovarian hyperstimulation syndrome. Fertil Steril. 2010;93(1):270-1.

19. Lin S, Li R, Chi H, Huang S, Zhang H, Zheng X, et al. Effect of ABO blood type on ovarian reserve in Chinese women. Fertil Steril. 2014;102(6):1729-32.

20. Şengül Ö, Dilbaz B, Yerebasmaz N, Dede S, Altınbaş S, Erkaya S. Only female age, and not blood type, is associated with ovarian reserve. Int J Fertil Steril. 2014;8(2): 143-6.

21. Spitzer D, Corn C, Stadler J, Wirleitner B, Schuff M, Vanderzwalmen $\mathrm{P}$, et. al. Implications of blood type for ovarian reserve and infertility - impact on oocyte yield in IVF patients. Geburtshilfe Frauenheilkd. 2014;74(10): 928-32. 